\title{
Health Economics in Breast Cancer
}

\author{
Matthias W. Beckmann Michael P. Lux \\ Frauenklinik, Universitätsklinikum Erlangen, Friedrich-Alexander-Universität Erlangen-Nürnberg, Germany
}

According to current data from the Robert Koch Institute, each year 71,660 women develop breast cancer in Germany. The annual mortality of patients with breast cancer is 17,209. Considering these figures and assuming a 10-year follow-up period to the end of the disease, it is evident that there are at present over half a million women receiving care for this condition in Germany. In addition, it is estimated that 60,000 of these women are suffering from metastatic breast cancer. According to data from the Federal Office of Statistics, breast cancer is the most frequent cause of death due to malignant disease in women, and is the fourth most frequent cause of death in women overall.

Since at present the German population comprises $36,175,549$ adult women, this means that 1 in every 72 women is receiving care for breast cancer from the oncological medical services. In view of these figures, it quickly becomes clear that diagnosis, treatment, and follow-up for patients with breast carcinoma are matters of immense importance for health-care policy and health economics - both in the adjuvant and palliative settings, and, in particular, in the area of prevention.

The cost of treatment for patients with metastatic disease has risen dramatically over the last few years - due on the one hand to the targeted therapies that are now available, and on the other to longer survival times, and thus longer periods of cost-intensive care. It is, therefore, more important than ever in this area to have cost-effectiveness analyses that take account not only of survival time and time to progression, but also of the quality of life for the patient - the primary goal in palliative care. Alongside the findings of clinical studies on promising new drugs, the results of health-economics evaluations may provide support for decisions for or against a given treatment. Adjuvant therapy is becoming increasingly important in relation to health economics when considering the cost-intensive situation of metastatic disease. Only optimal and quality-assured adjuvant therapy can prevent recurrences and metastases, and thus reduce the ensuing costs. Oncological care services for adjuvant patients therefore require additional investment, not cuts.

\section{KARGER}

Fax +497614520714

Information@Karger.com

www.karger.com
(C) 2013 S. Karger GmbH, Freiburg

$1661-3791 / 13 / 0081-0005 \$ 38.00 / 0$

Accessible online at:

www.karger.com/brc
Unfortunately, examples of cuts are not hard to find. Increasing cuts in the periods of hospitalization after surgery are currently the focus of health insurers and the Medical Service of the Health Insurance Funds (Medizinischer Dienst der Krankenkassen, MDK). However, while the potential savings for funding bodies are only marginal relative to overall care provision, the reduced hospitalization period represents an additional burden for the certified medical centers that have been set up through the breast centers and are now universally established in Germany. These are now offering diagnosis and treatment at the highest level, and are achieving a demonstrably better quality of results. On the other hand, they require considerable resources for coordination, documentation, and quality assurance, although in most cases they receive no additional finance for these. A rethinking of health-care economics is required here; this has already been recognized to some extent by health-care policy makers and is being implemented in the framework of the National Cancer Plan. The increasing blurring of sectors, with outpatient and inpatient areas no longer being able to be considered separately, indicates that further changes are required. Functioning network links between inpatient and outpatient facilities represent the way forward here. The outpatient field also needs to be strengthened - both in the specialty of gynecological oncology, and with regard to documentation and quality assurance, since a substantial proportion of treatment and follow-up takes place outside the inpatient facilities. The clinical cancer registries need to be further expanded in this context, to relieve the burden on health-care providers and to save substantial monetary resources through optimized processes. The legislative situation following the new Cancer Plan Implementation Law (Krebsplan-Umsetzungsgesetz) is therefore of particular importance here.

In particular, through optimized diagnosis, tumors can be identified at an earlier, more favorable stage, thus reducing the high subsequent costs. Thus, the mammography screening, which has now been universally implemented in Germany, is also of great importance in health-economics terms and in relation to costs. 
The many health-economics aspects of care for a patient with breast carcinoma mentioned above stand in strong contrast to the truly insufficient data on the topic from research studies, analyses, and evaluations. Everyone is talking about costs, but very few see them as a potential focus for scientific research. This is the justification for devoting a special issue of this journal to the topic. The emphasis of this issue is on the various points of view involved. In addition to basic healthcare economics [1], the viewpoint of the certified breast centers is considered [2], as well as those of the outpatient networks [3], diagnostic facilities in the context of mammo- graphy screening [4], and business management [5] (which still appears to be foreign to some medical specialists). In particular, the point of view of the patients, whose care must not be allowed to become the plaything of debates over costs, is presented [2]. All of these different points of view need to be integrated, so that the funding bodies and MDK can gain a picture of evidence-based health care [6]. The aim is therefore not only to hold discussions, but to reach an understanding on the basis of the available data on the health-economics situation and to work out possible solutions in a constructive dialogue - for the benefit of the patients.

\section{References}

1 Jacobs V, Bogner G, Schausberger CE, Reitsamer R, Fischer T: Relevance of health economics in breast cancer treatment - integration of economics in management of breast cancer at clinic level. Breast Care 2013;8: DOI: 10.1159/000348370.

2 Lux MP, Hildebrandt T, Beyer-Finkler E, Bani MR, Loehberg CC, Jud SM, Rauh C, Schrauder MG Fasching PA, Beckmann MW: Relevance of health economics in breast cancer treatment - the view of certified breast centres and their patients. Breast Care 2013;8: DOI: 10.1159/000347098.
3 Heinrich G, Hindenburg HJ, Schilling J, Klare P: Relevance of health economics in the medical treatment of breast cancer: the view of the professional association of practicing gynecologic oncologists e.V. (BNGO). Breast Care 2013;8: DOI: $10.1159 / 000346856$.

4 Uleer C, Wagner J, Moisidis-Tesch C: Relevance of health economics in the early detection of breast cancer in Germany - the view of the German society of gynecologic oncologists in practice (BNGO). Breast Care 2013;8: DOI:10.1159/000348358.
5 Seidel RP, Lux MP, Hoellthaler J, Beckmann MW, Voigt W: Economic constraints - the growing challenge for western breast cancer centers. Breast Care 2013;8: DOI: 10.1159/000348356.

6 Zimmer B, Heyll A: Health economic aspects of breast cancer treatment: the compulsory health insurances' view. Breast Care 2013;8: DOI: $10.1159 / 000346985$. 